\title{
Transient response of a laminated sandwich plate with viscoelastic core subjected to air blast: theory and experiment
}

\author{
D. Balkan, O. Acar, H. S. Türkmen \& Z. Mecitoğlu \\ Faculty of Aeronautics and Astronautics, Istanbul Technical University, \\ Turkey
}

\begin{abstract}
This paper is focused on the theoretical and experimental study of the dynamic behavior of sandwich composite plates with a viscoelastic core subjected to blast load. The sandwich plate has carbon/epoxy face sheets and an aramid honeycomb core. The clamped boundary conditions are considered for all edges of the plate. The sandwich plate is modeled using first order shear deformation theory considering the geometrical nonlinearities. The equations of motion are derived by the use of the virtual work principle for the sandwich plate. The viscoelastic behavior is modeled by using the Kelvin-Voigt theory. The equations of motion are reduced into the time domain using Galerkin's method. The nonlinear-coupled equation system is solved by Mathematica Software. In the experimental study, the pressurized air in a shock tube is impinged on the sandwich composite plate by rupturing a membrane in front of the shock tube. The strain-time histories obtained from the theoretical analysis are compared with the experimental ones and a good agreement is found.
\end{abstract}

Keywords: blast load, Kelvin-Voigt model, Galerkin's method.

\section{Introduction}

Sandwich plates have been used extensively in the aircraft industry, both in civil and military aircraft, since 1940 [1]. They have now begun to be used in the structure of missiles and satellites. The use of sandwich materials in military structures is also growing rapidly. 
Composite materials themselves, which are used as faced sheets of the sandwich plate, have damping properties due to fiber-matrix interactions. However, these damping levels are not high enough to safeguard the structure. Therefore, in the construction of sandwich composite plate, a core material with high viscoelastic damping capability can be used or some viscoelastic layers can be placed in addition to the conventional core layer.

Several studies for sandwich constructions are reviewed in the literature [3-5]. However, only a few studies in the nonlinear response of laminated sandwich composite plates subjected to blast load are investigated. Hause and Librescu [6] considered the response of anisotropic sandwich flat panels to explosive pressure pulses. Librescu et al. [7] investigated the linear and nonlinear dynamic response of sandwich panels under blast load. Dynamic responses of sandwich flat panels to time-dependent loads generated by an underwater and by a shock wave are considered by Librescu et al. [8]. Hause and Librescu [9] investigated the dynamic response of doubly curved anisotropic sandwich panels exposed to time-dependent loads. The nonlinear dynamic response of a sandwich plate subjected to blast load is investigated by Baş et al. [10].

Although there are a numerous studies considering the blast load effects on sandwich composite plates with various core configurations in the open literature, no study is found that examines the effects of a viscoelastic core on the dynamic behavior of sandwich plates under blast load. Furthermore, the no experimental works related to the subject are found in the literature. Esmailzadeh and Jalali [16] studied nonlinear oscillations of viscoelastic simply supported rectangular plates by assuming the Voigt-Kelvin constitutive model. Yan Wei et al. [13] investigated the three dimensional solution of a laminated orthotropic rectangular plate with viscoelastic interfaces, described by the Kelvin-Voigt model. Mesquita and Coda [14] considered an alternative Kelvin Viscoelastic formulation for the finite element method. Lekszycki et al. [15] characterized the constitutive parameters of the Voigt model and described viscoelastic materials applied in sandwich beams.

In the theoretical study, the equations of motion are derived by the use of the virtual work principle for a sandwich composite plate with a viscoelastic core. The sandwich plate is modeled using first order shear deformation theory. The geometrical nonlinearities are considered in the derivations. The viscoelastic behavior is modeled by using the Kelvin-Voigt linear viscoelastic theory. A system of five nonlinear equations is obtained. The displacement field in the space domain is approximated by the trial functions and then the equations of motion are reduced into the time domain using Galerkin's method. The nonlinear-coupled equation system in the time domain is solved by Mathematica Software and the results of theoretical analyses are obtained.

In the experimental study, a special experimental setup is used for the blast test.

The pressurized air in a shock tube is impinged on the sandwich composite plate by rupturing a membrane in front of the shock tube. The pressure distribution on the plate is obtained by using the pressure sensors placed at specific points on the plate. The straingages are used to obtain strain time 
histories at certain locations on the sandwich plate. The strain-time histories obtained from the theoretical analysis are compared with the experimental ones and a good agreement is found.

\section{Equation of motion}

The rectangular sandwich plate with the length $a$, the width $b$ and the thickness $h$ is shown in figure 1. Cartesian coordinate system is used to derive the equations.

As it is mentioned in the Weierstrass theorem [11], "Any function which is continuous in an interval may be approximated uniformly by polynomials in this interval". So displacement field can be represented as follows:

$$
\begin{aligned}
& u(x, y, z, t)=u_{0}(x, y, t)+z \alpha_{1}(x, y, t)+z^{2} \alpha_{2}(x, y, t)+\ldots \\
& v(x, y, z, t)=v_{0}(x, y, t)+z \beta_{1}(x, y, t)+z^{2} \beta_{2}(x, y, t)+\ldots \\
& w(x, y, z, t)=w_{0}(x, y, t)+z \gamma_{1}(x, y, t)+z^{2} \gamma_{2}(x, y, t)+\ldots
\end{aligned}
$$

The Kirchhoff-Love Hypothesis for linear elastic thin plates results in the linearly distributed tangential displacements and a constant normal displacement through the thickness of the plate. So Eq.1 can be written as follows:

$$
\begin{gathered}
u(x, y, z, t)=u_{0}(x, y, t)+z \alpha_{1}(x, y, t) \\
v(x, y, z, t)=v_{0}(x, y, t)+z \beta_{1}(x, y, t) \\
w(x, y, z, t)=w_{0}(x, y, t)
\end{gathered}
$$

Here $\mathrm{x}, \mathrm{y}, \mathrm{z}$ represent Cartesian coordinates. $\mathrm{u}, \mathrm{v}, \mathrm{w}$ indicate the displacements in the $\mathrm{x}, \mathrm{y}, \mathrm{z}$ directions, respectively; $\mathrm{u}_{0}, \mathrm{v}_{0}, \mathrm{w}_{0}$ denote the displacement of a point on the neutral surface of plate. $\alpha_{1}, \beta_{1}$ are rotations about

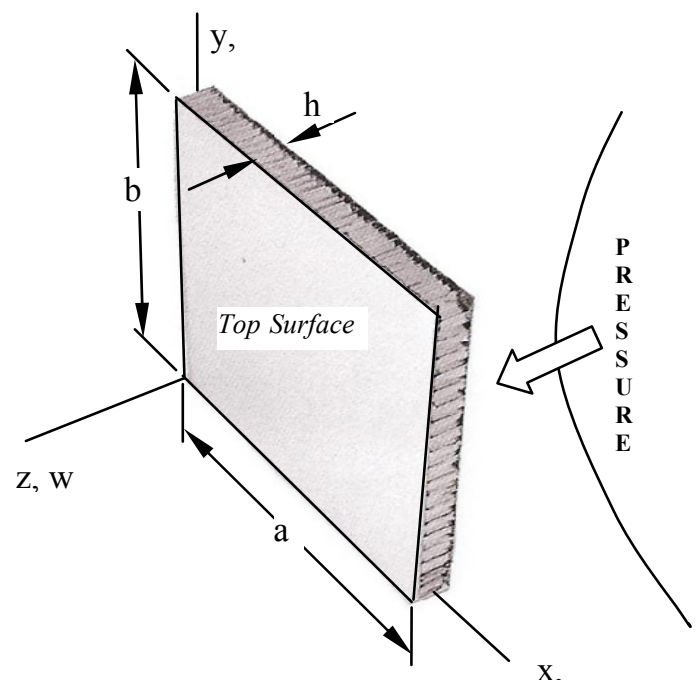

Figure 1: Sandwich composite plate and its coordinate system. 
transverse normals. "The transverse normals do not remain perpendicular to the midsurface after deformation". Kirchhoff's assumption is not valid for the first order shear deformation theory [1].

The rotation functions for thin plates can be written as follows:

$$
\alpha_{1}=-\frac{\partial w_{0}}{\partial x}, \beta_{1}=-\frac{\partial w_{0}}{\partial y}
$$

The strain-displacement relations for the von Kármán Plate can be written as:

$$
\begin{aligned}
& \varepsilon_{x x}=\frac{\partial u_{0}}{\partial x}+\frac{1}{2}\left(\frac{\partial w_{0}}{\partial x}\right)^{2}+z \frac{\partial \alpha_{1}}{\partial x} \\
& \varepsilon_{y y}=\frac{\partial v_{0}}{\partial y}+\frac{1}{2}\left(\frac{\partial w_{0}}{\partial y}\right)^{2}+z \frac{\partial \beta_{1}}{\partial y} \\
& \varepsilon_{x y}=\frac{\partial v_{0}}{\partial x}+\frac{\partial u_{0}}{\partial y}+\left(\frac{\partial w_{0}}{\partial x} \frac{\partial w_{0}}{\partial y}\right)+z\left(\frac{\partial \beta_{1}}{\partial x}+\frac{\partial \alpha_{1}}{\partial y}\right) \\
& \gamma_{x z}=\frac{\partial w_{0}}{\partial x}+\alpha_{1} \\
& \gamma_{y z}=\frac{\partial w_{0}}{\partial y}+\beta_{1} \\
& \varepsilon_{z z}=0
\end{aligned}
$$

$\varepsilon_{x x}, \varepsilon_{y y}, \varepsilon_{z z}$ indicates strains in $\mathrm{x}, \mathrm{y}$ and $\mathrm{z}$ directions, respectively.

Constitutive equations are derived considering linear viscoelastic behavior that is modeled by the Kelvin-Voigt linear viscoelastic theory [12].

$$
\sigma(t)=E \varepsilon(t)+\eta \frac{\partial \varepsilon(t)}{\partial t}
$$

For composite materials, stress-strain equations can be written as follows [16]:

$$
\begin{aligned}
& \left\{\begin{array}{l}
\sigma_{x x} \\
\sigma_{y y} \\
\sigma_{x y}
\end{array}\right\}=\left[\begin{array}{lll}
\bar{Q}_{11} & \bar{Q}_{12} & \bar{Q}_{16} \\
\bar{Q}_{12} & \bar{Q}_{22} & \bar{Q}_{26} \\
\bar{Q}_{16} & \bar{Q}_{26} & \bar{Q}_{66}
\end{array}\right]^{[k]}\left\{\begin{array}{l}
\varepsilon_{x x} \\
\varepsilon_{y y} \\
\varepsilon_{x y}
\end{array}\right\}+\eta \frac{\partial}{\partial t}\left\{\left[\begin{array}{lll}
\bar{Q}_{11} & \bar{Q}_{12} & \bar{Q}_{16} \\
\bar{Q}_{12} & \bar{Q}_{22} & \bar{Q}_{26} \\
\bar{Q}_{16} & \bar{Q}_{26} & \bar{Q}_{66}
\end{array}\right]^{[k]}\left\{\begin{array}{l}
\varepsilon_{x x} \\
\varepsilon_{y y} \\
\varepsilon_{x y}
\end{array}\right\}\right\} \\
& \left\{\begin{array}{l}
\sigma_{y z} \\
\sigma_{x z}
\end{array}\right\}^{[k]}=\left[\begin{array}{ll}
\bar{Q}_{44} & \bar{Q}_{45} \\
\bar{Q}_{45} & \bar{Q}_{55}
\end{array}\right]^{[k]}\left\{\begin{array}{l}
\gamma_{y z} \\
\gamma_{x z}
\end{array}\right\}+\eta \frac{\partial}{\partial t}\left\{\left[\begin{array}{ll}
\bar{Q}_{44} & \bar{Q}_{45} \\
\bar{Q}_{45} & \bar{Q}_{55}
\end{array}\right]^{[k]}\left\{\begin{array}{l}
\gamma_{y z} \\
\gamma_{x z}
\end{array}\right\}\right\} \\
& \left\{\begin{array}{l}
Q_{y} \\
Q_{x}
\end{array}\right\}=\kappa\left\{\left[\begin{array}{ll}
A_{44} & A_{45} \\
A_{45} & A_{55}
\end{array}\right]\left\{\begin{array}{l}
\gamma_{y z} \\
\gamma_{x z}
\end{array}\right\}+\eta \frac{\partial}{\partial t}\left\{\left[\begin{array}{cc}
A_{44} & A_{45} \\
A_{45} & A_{55}
\end{array}\right]\left\{\begin{array}{l}
\gamma_{y z} \\
\gamma_{x z}
\end{array}\right\}\right\}\right\}
\end{aligned}
$$


$\bar{Q}_{i j}$ and $A_{i j}$ are stiffness matrix coefficients of sandwich materials.

For layered or sandwich composite plates, stress resultants can be integrated through the thickness of the each layer [17]. Then, stress and strain resultants can be obtained.

$\{\mathbf{N}\}$ and $\{\mathbf{M}\}$ are the vectors of force and moment components, respectively.

Coefficient in the matrices are given by [1],

$$
\begin{aligned}
D_{i j} & =\frac{1}{3} \sum_{k=1}^{n}\left(\bar{Q}_{i j}\right)_{k}\left(h_{k}{ }^{3}-h_{k-1}{ }^{3}\right) \\
A_{i j} & =\sum_{k=1}^{n}\left(\bar{Q}_{i j}\right)_{k}\left(h_{k}-h_{k-1}\right) \\
B_{i j} & =\frac{1}{2} \sum_{k=1}^{n}\left(\bar{Q}_{i j}\right)_{k}\left(h_{k}{ }^{2}-h_{k-1}{ }^{2}\right)
\end{aligned}
$$

\section{Governing equation}

The equations of motion are derived by the use of virtual work principle for a sandwich composite plate with a viscoelastic core.

$$
\int_{0}^{T}(\delta U+\delta V+\delta K) d t=0
$$

$\delta U$ is virtual strain energy, $\delta V$ is virtual work done by external applied forces, $\delta K$ is virtual kinetic energy are given by

$$
\begin{aligned}
& \delta U=\int_{\Omega_{0}}\left\{\int_{-h / 2}^{h / 2}\left[\sigma_{x x} \delta \varepsilon_{x x}+\sigma_{y y} \delta \varepsilon_{y y}+\sigma_{x y} \delta \gamma_{x y}+\sigma_{x z} \delta \gamma_{x z}+\sigma_{y z} \delta \gamma_{y z}\right] d z\right\} d x d y \\
& \delta V=-\int_{\Omega_{0}}\left[q_{x} \delta u+q_{y} \delta v+\left(q_{b}+q_{t}\right) \delta w\right] d x d y \\
& \delta K=\int_{\Omega_{0}} \bar{m}(\dot{u} \delta \dot{u}+\dot{v} \delta \dot{v}+\dot{w} \delta \dot{w}) d x d y
\end{aligned}
$$

$q_{b}$ and $q_{t}$ are the distributed forces at the bottom and at the top surfaces. $q_{x}$ and $q_{y}$ are distributed force components in the $\mathrm{x}$ and $\mathrm{y}$ directions. In virtual kinetic energy equation, exponentially used $\operatorname{dot}\left({ }^{\circ}\right)$ represents time derivatives.

Substituting for the virtual strains from Eq. (5) into Eq. (6) the governing equations of the plate are obtained in integral form.

$$
\begin{aligned}
& \frac{\partial N_{x x}}{\partial x}+\frac{\partial N_{x y}}{\partial y}=I_{0} \frac{\partial^{2} u_{0}}{\partial t^{2}}+I_{1} \frac{\partial^{2} \alpha_{1}}{\partial t^{2}}+q_{x} \\
& \frac{\partial N_{x y}}{\partial x}+\frac{\partial N_{y y}}{\partial y}=I_{0} \frac{\partial^{2} v_{0}}{\partial t^{2}}+I_{1} \frac{\partial^{2} \beta_{1}}{\partial t^{2}}+q_{y}
\end{aligned}
$$




$$
\begin{gathered}
\frac{\partial Q_{x}}{\partial x}+\frac{\partial Q_{y}}{\partial y}+\frac{\partial}{\partial x}\left(N_{x x} \frac{\partial w_{0}}{\partial x}+N_{x y} \frac{\partial w_{0}}{\partial y}\right)+\frac{\partial}{\partial y}\left(N_{x y} \frac{\partial w_{0}}{\partial x}+N_{y y} \frac{\partial w_{0}}{\partial y}\right)+q_{z}=I_{0} \frac{\partial^{2} w_{0}}{\partial t^{2}} \\
\frac{\partial M_{x x}}{\partial x}+\frac{\partial M_{x y}}{\partial y}-Q_{x}=I_{2} \frac{\partial^{2} \alpha_{1}}{\partial t^{2}}+I_{1} \frac{\partial^{2} u_{0}}{\partial t^{2}} \\
\frac{\partial M_{x y}}{\partial x}+\frac{\partial M_{y y}}{\partial y}-Q_{y}=I_{2} \frac{\partial^{2} \beta_{1}}{\partial t^{2}}+I_{1} \frac{\partial^{2} v_{0}}{\partial t^{2}}
\end{gathered}
$$

$I_{0}$ is normal moment of inertia coefficient, $I_{2}$ is rotary moment of inertia coefficient and $I_{1}$ is normal and rotary moment of inertia coefficient. Here, $\mathrm{q}_{\mathrm{z}}$ is the distributed load in the $\mathrm{z}$ direction, which is summation of $\mathrm{q}_{\mathrm{b}}$ and $\mathrm{q}_{\mathrm{t}}$. In this study $\mathrm{q}_{\mathrm{z}}$ is the blast pressure and it is approximated by the following function,

$$
q_{z}(x, y, t)=\left[1-\cos \left(\frac{2 \pi t}{t_{e}}\right)\right]^{f}\left\{\frac{P_{t}+P_{e}}{2^{f} 2^{g} 2^{s}}\left[1-\cos \left(\frac{2 \pi x}{a}\right)\right]^{g}\left[1-\cos \left(\frac{2 \pi y}{b}\right)\right]^{s}-\frac{P_{e}}{2^{f}}\right\}
$$

Here $P_{t}$ is the peak pressure, $P_{e}$ is the suction pressure measured at the side section of the plate, $t_{e}$ is positive phase duration. $f, g, s$ are the adjustable parameters in order to obtain and appropriate pressure function matching the experimental pressure data.

\section{Solution method}

The displacement functions are chosen by considering clamped boundary conditions and given as follows.

$$
\begin{aligned}
& u_{0}=\sum_{m=1}^{M} \sum_{n=1}^{N} U_{m n}(t) \sin \frac{2 m \pi x}{a}\left(1-\cos \frac{2 n \pi y}{b}\right) \\
& v_{0}=\sum_{m=1}^{M} \sum_{n=1}^{N} V_{m n}(t)\left(1-\cos \frac{2 m \pi x}{a}\right) \sin \frac{2 n \pi y}{b} \\
& w_{0}=\sum_{m=1}^{M} \sum_{n=1}^{N} W_{m n}(t)\left(1-\cos \frac{2 m \pi x}{a}\right)\left(1-\cos \frac{2 n \pi y}{b}\right) \\
& \alpha_{0}=\sum_{m=1}^{M} \sum_{n=1}^{N} \Lambda_{m n}(t) \sin \frac{2 m \pi x}{a}\left(1-\cos \frac{2 n \pi y}{b}\right) \\
& \beta_{0}=\sum_{m=1}^{M} \sum_{n=1}^{N} \Psi_{m n}(t)\left(1-\cos \frac{2 m \pi x}{a}\right) \sin \frac{2 n \pi y}{b}
\end{aligned}
$$

Accounting the first terms of the displacement functions, the Galerkin's Method is applied to Eq. (7) and time dependent nonlinear differential equations are obtained. 


$$
\begin{aligned}
& a_{0} U+a_{1} V+a_{2} W^{2}+a_{3} \dot{U}+a_{4} W \dot{W}+a_{5} \dot{V}+a_{6} \ddot{U}+a_{7} \ddot{\Lambda}=0 \\
& b_{0} U+b_{1} V+b_{2} W^{2}+b_{3} \dot{U}+b_{4} W \dot{W}+b_{5} \dot{V}+b_{6} \ddot{\Lambda}+b_{7} \ddot{\Psi}=0 \\
& c_{0} U W+c_{1} W^{3}+c_{2} V W+c_{3} W \dot{U}+c_{4} W \dot{V}+c_{5} W^{2} \dot{W}+c_{6} W+c_{7}+c_{8} \ddot{W}+c_{9} \Lambda+ \\
& c_{10} \Psi+c_{11} \dot{W}+c_{12} \dot{\Lambda}+c_{13} \dot{\Psi}=0 \\
& d_{0} W+d_{1} \Lambda+d_{2} \Psi+d_{3} \dot{W}+d_{4} \dot{\Lambda}+d_{5} \dot{\Psi}+d_{6} \ddot{U}+a_{7} \ddot{\Lambda}=0 \\
& e_{0} W+e_{1} \Lambda+e_{2} \Psi+e_{3} \dot{\Psi}+e_{4} \dot{\Lambda}+e_{5} \dot{\Psi}+e_{6} \ddot{V}+e_{7} \ddot{\Psi}=0
\end{aligned}
$$

The nonlinear-coupled equation system in the time domain is solved by Mathematica Software, which uses the RKF45 solver, and the results of theoretical analyses are obtained. The results were compared with experimental results.

\section{Experimental results}

The sandwich plate used in the experiment has two layers carbon/epoxy face sheets on each side and an aramid honeycomb core. The clamped boundary conditions are considered for all edges of the plate. The dimensions of plate are $\mathrm{a}=\mathrm{b}=300 \mathrm{~mm}$. The thickness of the plate core layer is $1.5 \mathrm{~mm}$ and the thickness of the face sheets are $0.332 \mathrm{~mm}$.

In the experimental study, a special experimental setup is used for the blast test (Figure 2). The pressurized air in a shock tube is impinged on the sandwich composite plate by rupturing a membrane in front of the shock tube. The pressure distribution on the plate is obtained by using the pressure sensors placed at specific points on the plate. The straingages are used to obtain strain time histories at certain locations on the sandwich plate.

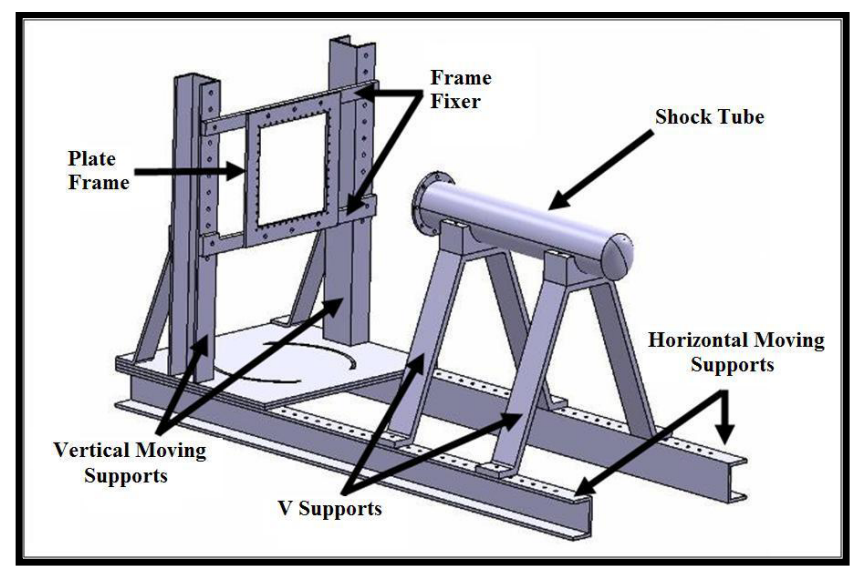

Figure 2: $\quad$ Experimental setup [24]. 
Three pressure sensors were placed in front side and two strain gauges were placed on the back side of sandwich plate. The location of the pressure sensors and strain gauges can be seen in Figure 3.

The sandwich plate has carbon/epoxy face sheets with two layers of $\left(0^{\circ} / 90^{\circ}\right)$ orientations and aramid core layer. Material properties of carbon/epoxy are given as $\mathrm{E}_{1}=45.5 \mathrm{GPa}, \mathrm{E}_{2}=45.5 \mathrm{GPa}, \mathrm{G}_{12}=2.7 \mathrm{GPa}, v_{12}=0.19$ and $\rho=1340 \mathrm{~kg} / \mathrm{m}^{3}$. Material properties of aramid core layer are taken as damping coefficient $\eta=$ $0.2, \mathrm{E}=25 \mathrm{MPa}, \mathrm{G}=1.5 \mathrm{MPa}, v=0.3$ and $\rho=32 \mathrm{~kg} / \mathrm{m}^{3}$. The nonuniform blast pressure is used in the analysis. Parameters obtained from the experiment are as follows: $\mathrm{P}_{\mathrm{t}}=54 \mathrm{kPa} \mathrm{P}_{\mathrm{e}}=5 \mathrm{kPa}, \mathrm{t}_{\mathrm{e}}=0.01 \mathrm{~s}$.

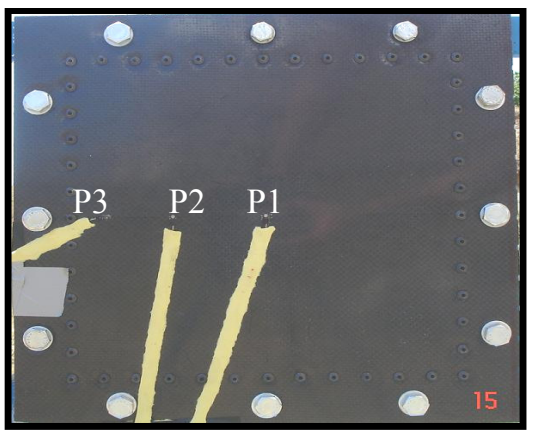

(a)

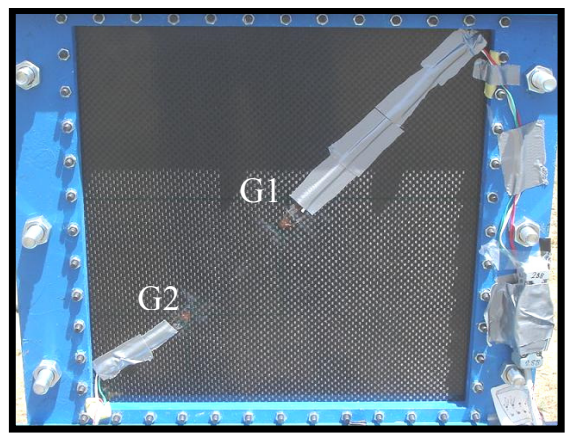

(b)

Figure 3: $\quad$ Location of sensors: (a) pressure sensors; (b) strain gauges.

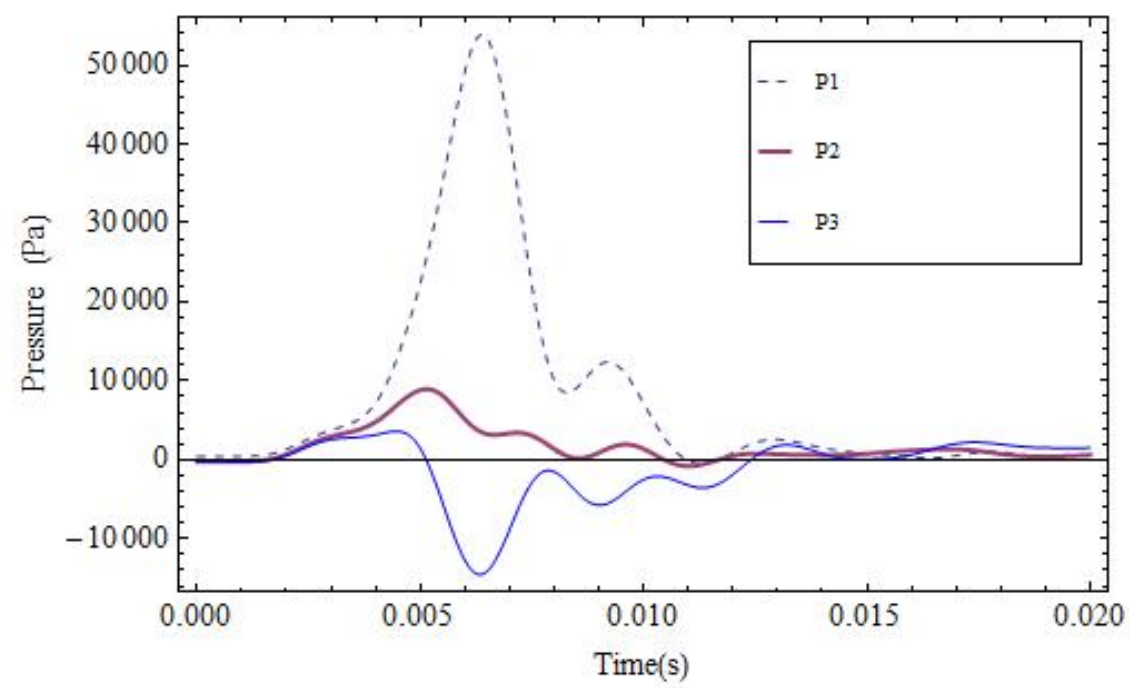

Figure 5: $\quad$ Pressure distribution at the location of pressure sensors. 


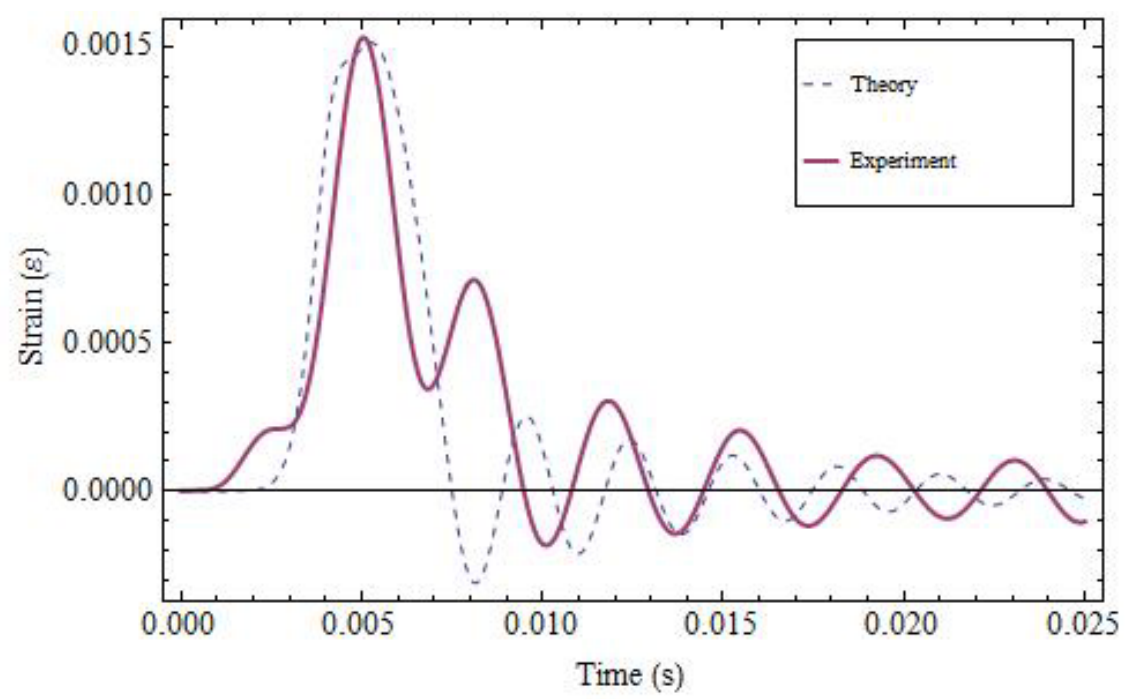

Figure 6: Time history of normal strain $\varepsilon_{\mathrm{x}}$ at the bottom center of the plate $\left(\mathrm{P}_{\mathrm{e}}=5 \mathrm{kPa}\right)$.

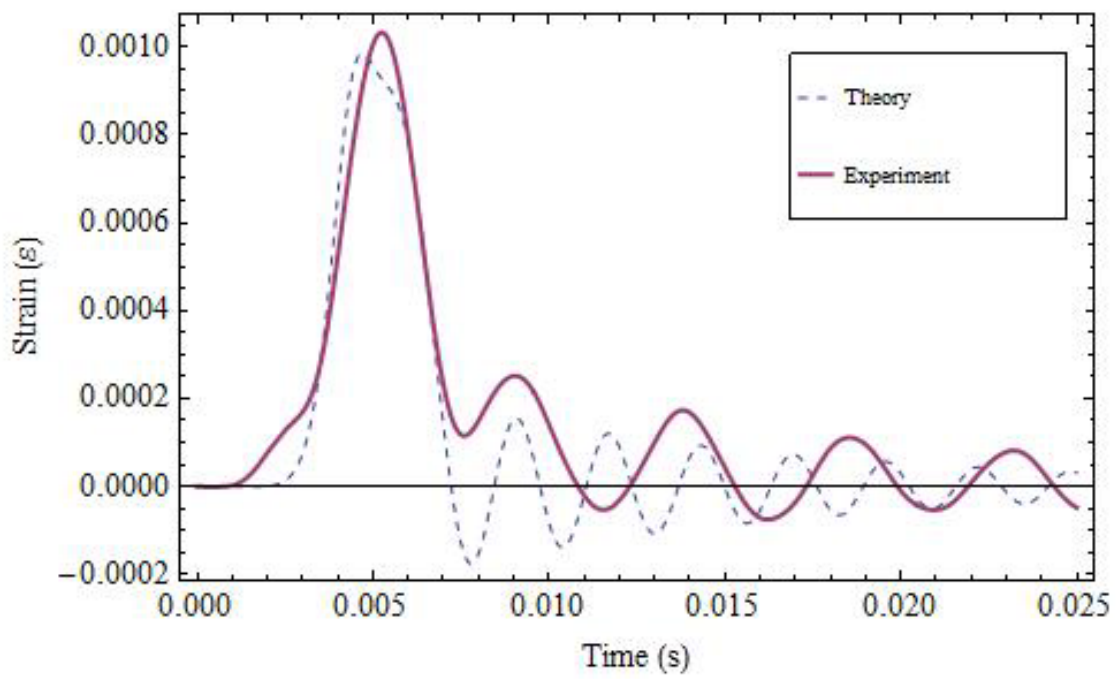

Figure 7: Time history of normal strain $\varepsilon_{\mathrm{x}}$ at the $\mathrm{G} 2$ location of the sandwich plate $\left(\mathrm{P}_{\mathrm{e}}=5 \mathrm{kPa}\right)$. 
The pressure distribution obtained from blast test can be seen in Figure 5 .

The results obtained from theoretical analysis are compared with experimental results in Figure 6.

The vibration frequencies are obtained from theoretical and numerical analysis are in good agreement but there is a phase shift. The peak amplitudes of normal strain are very approximate to each other.

\section{Conclusion}

In this study, transient dynamic behavior of sandwich composite plates with viscoelastic core under the blast load is studied. Sandwich plate has composite face layers and a viscoelastic core layer. The clamped boundary conditions are considered for all edges of the plate. The equations of motions are derived by the use of virtual work principle for a sandwich composite plate with a viscoelastic core.

In the experimental study, the pressurized air in a shock tube is impinged on the sandwich composite plate by rupturing a membrane in front of the shock tube. The strain-time histories obtained from the theoretical analysis are compared with the experimental ones and a good agreement is found for the peak values.

The blast pressure has peak value at the center of the plate and it decreases from center to the edges. The vibration amplitudes obtained from the experiment are higher than those of the approximate solution results. Moreover, the vibration frequencies obtained from the experiment is lower than the theoretical solution. It is observed that oscillations are damped instantly after the peak amplitude of the pressure.

\section{Acknowledgement}

This study was supported by The Support Programme for Scientific and Technological Research Project grant from TUBITAK.

\section{References}

[1] Allen, H. G., Analysis and Design of Structural Sandwich Panels, Pergamon Press: Oxford, 1969.

[2] Reddy, J. N., Mechanics of Laminated Composite Plates and Shells Theory and Analysis, CRC Press: Boca Raton, 2004b.

[3] Noor, A. K., Burton, W. S., and Bert, C. W., Computational Models for Sandwich Panels and Shells, Applied Mechanics Reviews, 4(3), pp. 155 199, 1996.

[4] Librescu, L., and Hause, T., Recent Development in the Modelling and Behavior of Advanced Sandwich Constructions: a survey, Journal of Composite Structures, 48(1-3), pp. 1-17, 2000.

[5] Vinson, J. R., Sandwich Structures, Applied Mechanics Reviews, 54(3), pp. 201-214, 2001. 
[6] Hause, T., and Librescu, L., Dynamics Response of Anisotropic Sandwich Flat Panels to Explosive Pressure Pulses, International Journal of Impact Engineering, 31, pp. 607-628, 2005.

[7] Librescu, L., Oh, S. Y., and Hohe, J., Linear and Non-linear dynamic response of sandwich panels to blast loading, Composites: Part B, 35, pp. 673-683, 2004.

[8] Librescu, L., Oh, S. Y., and Hohe, J., Dynamic Response of Anisotropic Sandwich Flat Panels to Underwater and in-air Explosions, International Journal of Solids and Structures, 43, pp. 3794-3816, 2006.

[9] Hause, T., and Librescu, L., Dynamic Response of Doubly-curved Anisotropic Sandwich Panels impacted by blast Loadings, International Journal of Solids and Structures, 43, pp. 6678-6700, 2007.

[10] Baş, A., Kazanc1, Z., and Mecitoğlu, Z., Nonlinear Response of A Sandwich Plate Subjected to Blast Load, ASME International Mechanical Engineering Congress and Exposition, November 11-15, (IMECE 2007), Seattle, Washington, USA, 2007.

[11] Weierstrass, K., Über die Analytische Darstellbarkeit Sogenannter Willkürlicher Functionen Einer Reellen Veränderlichen, Sitzungsberichte de Akademie zu Berlin, pp. 633-639, 789-805: also appeared in Weierstrass' Mathematische Werke, 1903, Mayer and Muller, Berlin, 3, pp. 1-37, 1885.

[12] Shaw, M. T., MacNight, W. J, Introduction to Polymer Viscoelasticity, John Wiley \& Sons, Inc.: Hoboken, New Jersey, 2005.

[13] Yan Wei, Ying Ji, Chen Weiqiu, A Three-Dimensional Solution for Laminated Orthotropic Rectangular Plates with Viscoelastic Interfaces, Acta Mechanica Solida Sinica, Vol. 19, No. 2, June 2006.

[14] Mesquita, A. D., Coda, H. B., Alternative Kelvin Viscoelastic Procedure for Finite Elements, Applied Mathematical Modelling, Vol. 26, 2002, pp. 501-516.

[15] Lekszycki, T., Olhoff, N., and Pedersen, J. J., Modelling and Identification of Viscoelastic Properties of Vibrating Sandwich Beams, Composite Structures, Vol. 22, pp. 15-31, 1992.

[16] Esmailzadeh, E., Jalali, M. A., Nonlinear Oscillation of Viscoelastic Rectangular Plates, Nonlinear Dynamics, 18, 311-319, 1999.

[17] Vinson, J. R., The Behavior of Sandwich Structures of Isotropic and Composite Materials, Technomic Publishing Company: USA, 1999.

[18] Ward, I. M., Hadley, D. W., An Introduction to the Mechanical Properties of Solid Polymers, John Wiley \& Sons, England, 1993.

[19] Zenkert, D., An Introduction to Sandwich Construction, Chameleon Press Ltd: London, UK, 1995.

[20] Türkmen, H. S., Katmanlı Kompozit Panellerin Anlık Basınç Yüküne Dinamik Cevabı, PhD. Thesis, p. Xvii+70, İstanbul Technical University, İstanbul, 1997.

[21] Bertholet, J., Composite Materials: Mechanical Behavior and Structural Analysis, Springer: New York, 1999.

[22] Jones, R., Mechanics of Composite Materials, Taylor \& Francis Inc., Philadelphia, 1998. 
124 Structures Under Shock and Impact XI

[23] Gupta, A. D., Gregory, F. H., Bitting, R. L., and Bhattacharya, S., Dynamic Analysis of an Explosively Loaded Hinged Rectangular Plate, Computers and Structures, Vol. 26, No. 1-2 Aug. 987, pp. 339-344.

[24] Baş, A., Hibrit Katmanlı Kompozit Plakların Anlık Basınç YüküAltındaki Davranışının Deneysel ve Sayısal İncelenmesi, MS. Thesis, p. Iv+85, İstanbul Technical University, İstanbul, 2009. 